\title{
COMMUNICATION
}

\section{Solar thermal decomposition of desalination reject brine for carbon dioxide removal and neutralisation of ocean acidity}

\author{
P. A. Davies ${ }^{a}$
}

Received ooth January 2012,

Accepted ooth January 2012

DOI: $10.1039 /$ xoxxooooox

www.rsc.org/

Desalination plants could become net absorbers (rather than net emitters) of $\mathrm{CO}_{2}$. Thermal decomposition of salts in desalination reject brine can yield $\mathrm{MgO}$ which, added to the ocean, would take up $\mathrm{CO}_{2}$ through conversion to bicarbonate. The process proposed here comprises dewatering of brine followed by decomposition in a solar receiver using a heliostat field.

Desalination currently provides some 30 billion $\mathrm{m}^{3} / \mathrm{yr}$ of freshwater worldwide and this output is growing at a rate of about $10 \%$ per year. ${ }^{1}$ Within a decade we can expect a doubling of output, resulting in additional electrical energy requirement of $10 \mathrm{GW}$ and $\mathrm{CO}_{2}$ emissions of $0.045 \mathrm{GtCO}_{2} / \mathrm{yr}$ (assuming state-of-the-art reverse osmosis [RO] technology with specific energy consumption of $3 \mathrm{kWh} / \mathrm{m}^{3}$ and electricity generated with carbon intensity $0.5 \mathrm{kgCO}_{2} / \mathrm{kWh}$ ). By $2030 \mathrm{a}$ shortfall in renewable freshwater of 2700 billion $\mathrm{m}^{3} / \mathrm{yr}$ is forecast, and this could drive an even more rapid growth in desalination capacity with associated energy demand and emissions. $^{2}$

One way to offset the emission of $\mathrm{CO}_{2}$ from a seawater desalination plant is to take advantage of the magnesium in the concentrated brine rejected by the plant. This could be converted to magnesium oxide which, discharged to the oceans, would gradually absorb ambient $\mathrm{CO}_{2}$ through conversion to magnesium carbonate or bicarbonate (Fig. 1). Each $\mathrm{m}^{3}$ of seawater contains $1.32 \mathrm{~kg}$ of $\mathrm{Mg}$ which is retained in the reject brine and could in principle absorb up to 4.76 $\mathrm{kg} / \mathrm{m}^{3}$ of $\mathrm{CO}_{2}$ if converted fully to $\mathrm{Mg}\left(\mathrm{HCO}_{3}\right)_{2}$. Fed to a desalination plant, $1 \mathrm{~m}^{3}$ of seawater typically provides $0.5 \mathrm{~m}^{3}$ of freshwater with $\mathrm{CO}_{2}$ emission of $0.75 \mathrm{~kg}$ associated with electricity usage of the plant (based on assumptions above). Thus the maximum $\mathrm{CO}_{2}$ absorption potential of the reject brine exceeds the $\mathrm{CO}_{2}$ emission from desalination by a factor of $>6$, resulting in a theoretical net absorption capacity per freshwater output of $8 \mathrm{~kg} \mathrm{CO}_{2} / \mathrm{m}^{3}$.
It is worth noting that the ocean provides a very large stock of magnesium for $\mathrm{CO}_{2}$ absorption. The top $100 \mathrm{~m}$ of the ocean is generally considered to be well mixed providing gaseous exchange with the atmosphere. Based on the maximum absorption capacity of $4.76 \mathrm{CO}_{2} / \mathrm{m}^{3}$, this top layer could absorb up to $170000 \mathrm{GtCO}_{2}$ - greatly exceeding the current excess stock of $900 \mathrm{GtCO}_{2}$ in the atmosphere. ${ }^{3}$

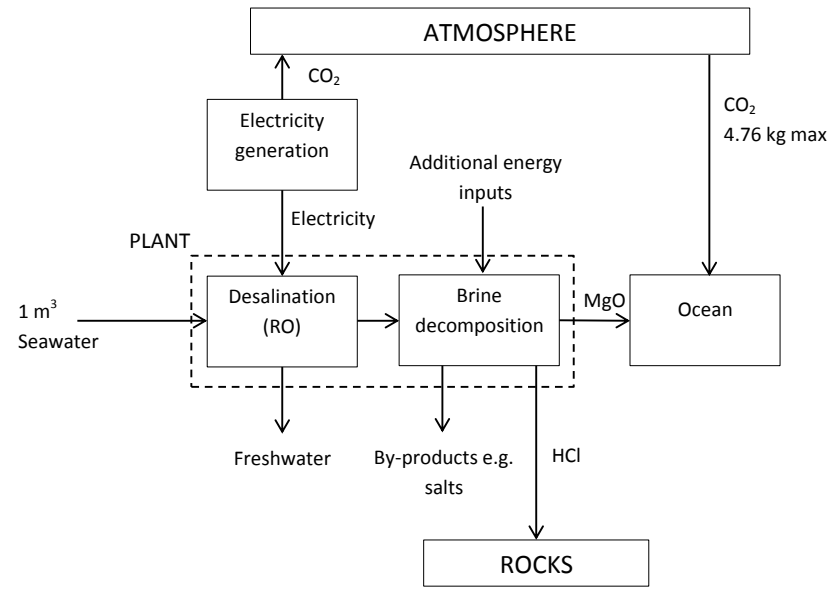

Fig 1: Concept of proposed process using desalination reject brine to absorb carbon dioxide from the atmosphere.

Reject brine is usually considered a harmful aspect of desalination because of its impact on the marine environment. ${ }^{4}$ To address this issue, researchers have investigated ways to manage and add value to this waste stream - including carbonation for $\mathrm{CO}_{2}$ sequestration. Ferrini et al ${ }^{5}$, for example, showed that addition of carbon dioxide to magnesium chloride solution in the presence of ammonia leads to formation of magnesium carbonate with ammonium chloride as a by-product. This method is interesting for the absorption of $\mathrm{CO}_{2}$ from point-source emitters. 
The alternative investigated in this study is to decompose reject brine such that the magnesium chloride is hydrolysed to magnesium oxide according to the endothermic reaction:

$$
\mathrm{MgCl}_{2}+\mathrm{H}_{2} \mathrm{O} \rightarrow \mathrm{MgO}+2 \mathrm{HCl}
$$

It is proposed that brine decomposition be carried out using solar thermal energy in the post-treatment stage of desalination (Fig 1). The $\mathrm{MgO}$ will be incorporated in the plant reject stream and returned to the ocean. This process may be considered a variant of the geothermal technology of 'ocean liming' which, as well as removing $\mathrm{CO}_{2}$, helps to neutralise ocean acidity. ${ }^{6}$ But instead of adding crushed minerals to the sea, the neutralising substance $(\mathrm{MgO})$ will be obtained from the seawater itself. The by-product of $\mathrm{HCl}$ can be sequestered by injecting hydrochloric acid into silicate rocks. The aim of this study is to investigate the feasibility of this proposition at the preliminary level. The study investigates experimentally the yield of $\mathrm{MgO}$ from thermal decomposition of seawater. It then presents and models a system for brine thermal decomposition (BTD) using a heliostat field. This includes estimates of the energy penalties involved and the land area needed. Finally, geological disposal of the hydrogen chloride is discussed. For the purpose of illustrating the results, we consider two examples: (i) a desalination plant of $10000 \mathrm{~m}^{3} /$ day freshwater output equipped with BTD; (ii) scale up to give additional global desalination output of 30 billion $\mathrm{m}^{3} / \mathrm{yr}$, corresponding to a doubling in current capacity.

\section{Yield of magnesium oxide from seawater}

Samples $(100 \mathrm{ml})$ of seawater were thermally decomposed, first by evaporation in a convection oven at $200^{\circ} \mathrm{C}$, and then by heating in a furnace at $450^{\circ} \mathrm{C}$ until hydrogen chloride was no longer evolved. The dry residue was dispersed in distilled water to make up the same initial volume of $100 \mathrm{ml}$ giving a milky white solution of $\mathrm{pH}$ 9.86. Titration against $\mathrm{HCl}$ showed $78 \%$ conversion of magnesium to $\mathrm{MgO}$. $\uparrow$ The $22 \%$ shortfall against stoichiometric yield can be explained by likely precipitation of magnesium sulphate (instead of chloride) which does not readily decompose.

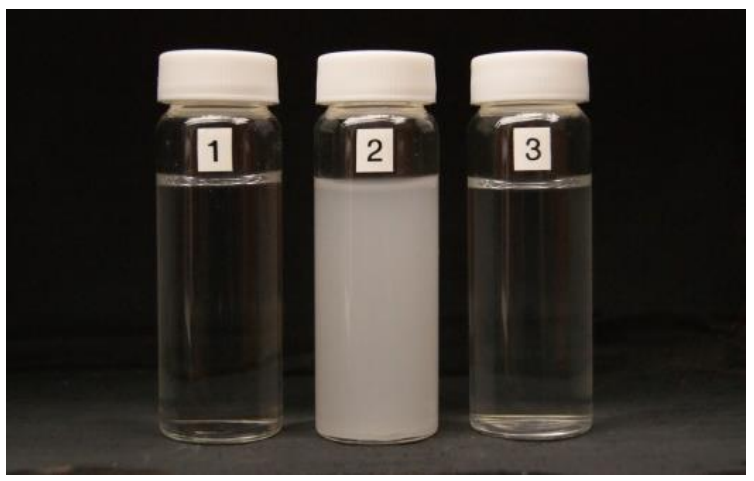

Fig 2: Thermal treatment of seawater yields $\mathrm{MgO}$ which absorbs $\mathrm{CO}_{2}$ : (1) raw seawater, (2) suspension of salts after thermal decomposition, (3) solubilised salts after subjecting to $\mathrm{CO}_{2}$ gas.
To confirm presence of $\mathrm{MgO}$ in the suspension and its potential to absorb $\mathrm{CO}_{2}$, accelerated carbonation was carried out by subjecting the suspension to pressurised $\mathrm{CO}_{2}$ at 4 bar for $17 \mathrm{hrs}$ at room temperature. The liquid became substantially clear indicating conversion to soluble magnesium bicarbonate (Fig 2).

\section{Process design and modelling}

The hydrolysis process of eq. 1 is preceded by dehydration of magnesium chloride. The overall reaction and its energy requirement may be summarised ${ }^{7}$ :

$$
\begin{array}{r}
\mathrm{MgCl}_{2} .6 \mathrm{H}_{2} \mathrm{O} \rightarrow \mathrm{MgO}+2 \mathrm{HCl}(\mathrm{g})+5 \mathrm{H}_{2} \mathrm{O}(\mathrm{l}) \\
\Delta \mathrm{H}^{0}=-283 \mathrm{~kJ} / \mathrm{mol}
\end{array}
$$

However, due to the low concentration of $\mathrm{MgCl}_{2}$, the enthalpy needed to evaporate all the water in the reject brine is 100 times larger than the above, making direct thermal decomposition of the brine impractical. The brine must be dewatered prior to thermal treatment. Methods of dewatering could include: (i) Solar evaporation ponds, which precipitate $\mathrm{NaCl}$ salt leaving a supernatant brine rich in $\mathrm{MgCl}_{2}$. Harvesting such brine is already standard practice in salt works and the salt by-product would have economic value. ${ }^{8}$ However, the salt production from desalination at the scale discussed here would be huge. For example, the scenario of additional 30 billion $\mathrm{m}^{3} / \mathrm{yr}$ desalination capacity with salt recovery would result in salt production of 1 billion t/yr which is 4 times current global production. ${ }^{9}$ The land required for the ponds would also be large. (ii) Seawater greenhouses to evaporate water from the brine, thus providing cooling for protected cultivation of crops. The crop production would be economically valuable and make efficient use of desalinated water. The main limitation would be that seawater greenhouses would not be suitable for concentrating brine by a factor of more than 2-3 (depending on ambient humidity) beyond which hygroscopicity of the brine would hinder evaporation and cooling. ${ }^{10}$ (iii) Nanofiltration (NF) would remove sodium chloride from the brine while concentrating the divalent ions i.e. magnesium and calcium. Nanofiltration like reverse osmosis requires work input for the high-pressure pumping. It is a compact process which could be used (or even retrofitted) with most desalination plant. (iv) Multiple effect distillation (MED) is another compact desalination process. It can handle strong brines and requires thermal energy input. MED will produce a small amount of freshwater additional to the reverse osmosis (RO) output.

These processes could be combined in various ways according to local requirements and land availability. In this study, we select NF and MED, these being the most generally applicable options. The proposed system (Fig 3) will dewater brine using NF followed by MED, prior to decomposition using concentrated solar thermal energy. The mass-energy balance for the whole system has been modelled using the 
assumptions of Table 2. Important aspects of each process are as follows.

\section{Nanofiltration}

It is proposed to use NF to reduce the brine volume by a factor of 10 , providing brine with magnesium chloride concentration of $10 \%$ (20 times that in raw seawater). Operation in 2 stages with intermediate booster pump and use of an energy recovery device will reduce the amount of energy input required for the process. The osmotic pressure of the magnesium chloride brine determines the energy requirements of pumping, and has been determined from published osmotic coefficients. ${ }^{11}$

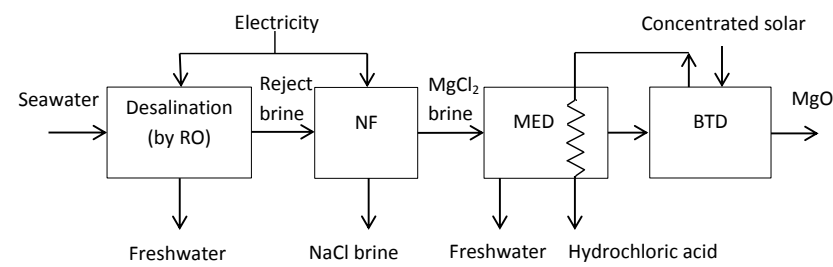

Fig 3: Desalination and downstream processes making up the plant in Fig. 1. Dewatering of reject brine by nanofiltration (NF) and then multiple effect distillation (MED) reduces the energy requirement of the subsequent brine thermal decomposition (BTD). The heat input for the MED is provided by condensing hydrochloric acid vapours from the decomposition process.

Table 2: Assumptions in modelling the four processes of Fig 3.

\section{General}

Carbon intensity electricity supply

Reverse Osmosis (RO)

Specific energy consumption

Recovery ratio

Nanofiltration $(N F)$

Number of stages

Recovery ratio each stage

Pump efficiency

Operating pressure/

osmotic pressure at brine outlet

Energy recovery device efficiency

Multiple Effect Distillation (MED)

Number of effects

Performance ratio

Brine thermal decomposition (BTD)

Gross power to receiver per land area* $\quad 25 \mathrm{~W} / \mathrm{m}^{2}$

Decomposition yield $^{\S} \quad 78 \%$

Solar receiver efficiency $\quad 90 \%$

Solar receiver temperature $\quad 550^{\circ} \mathrm{C}$

Solar receiver pressure
$0.5 \mathrm{kgCO}_{2} / \mathrm{kWh}$

$3 \mathrm{kWh} / \mathrm{m}^{3}$

0.5

2

0.7

$85 \%$

$120 \%$

$95 \%$

4

$<3$

3 bar abs

\section{Multiple effect distillation}

MED will be used to further concentrate the brine to $30 \%$, approaching saturation concentration of $35 \%$ (mass solute/mass solution). Use of multiple effects economises the energy input to the distillation process and increases the performance ratio (mass water output/steam input). MED has already been developed for seawater desalination using 12 effects to achieve performance ratio up to 16 with performance further enhanced using thermal vapour compression. For concentrated brine, however, the boiling point elevation limits the number of effects to 4 or 5 as illustrated in the T-P diagram of Fig 4. It is proposed to drive the MED with condensing hydrochloric acid vapour from the brine thermal decomposition. This means that thermal vapour compression cannot be used, as it would remix the hydrochloric acid with the brine. Consequently the performance ratio is assumed to be limited to below $3 .{ }^{12}$

Condensing hydrochloric acid is highly corrosive presenting challenges for the selection of materials for the MED unit. Specialised Ni-Mo alloys may be acceptable while more expensive $\mathrm{Zr}$ alloys have higher corrosion resistance. ${ }^{13} \mathrm{Kim}$ et al. used magnetron sputtering to prepare an amorphous $\mathrm{Cr}-\mathrm{Zr}$ alloy with 3-fold decreased corrosion rate compared to pure $\mathrm{Zr}$ with $6 \mathrm{M} \mathrm{HCl}^{14}$ This alloy could be used as a protective coating. Note that resistance to $\mathrm{HCl}$ is only required in the first effect of the MED unit, as in subsequent effects pure water and not $\mathrm{HCl}$ condenses. In all effects there is still a requirement to resist corrosion by concentrated $\mathrm{MgCl}_{2}$ solution, for which purpose more conventional materials such as titanium alloys may be used. ${ }^{13}$

\section{Brine thermal decomposition}

Though the energy requirement of BTD is large, temperatures required are modest $\left(300-600^{\circ} \mathrm{C}\right)$ such that the input can readily be supplied by solar energy. The reaction of eq. 2 occurs in several steps involving dehydration and decomposition of $\mathrm{MgCl}_{2}$ and intermediate magnesium hydroxychloride compounds. ${ }^{15}$ The last step is decomposition of $\mathrm{MgOHCl}^{7}$ :

$\mathrm{MgOHCl} \rightarrow \mathrm{MgO}+\mathrm{HCl}$

The viable temperature-pressure region for the decomposition is determined by the equilibrium constant of this reaction, which in turn determines the maximum allowable partial pressure of $\mathrm{HCl}$, and hence the allowable total pressure as determined by the molar concentrations of $\mathrm{HCl}$ and water in the vapours from decomposition (Fig 4). The choice of 3 bar as the decomposition pressure means that the temperature can be limited to $<600^{\circ} \mathrm{C}$ while the saturation temperature of the exiting vapour will remain high enough to drive the MED. 


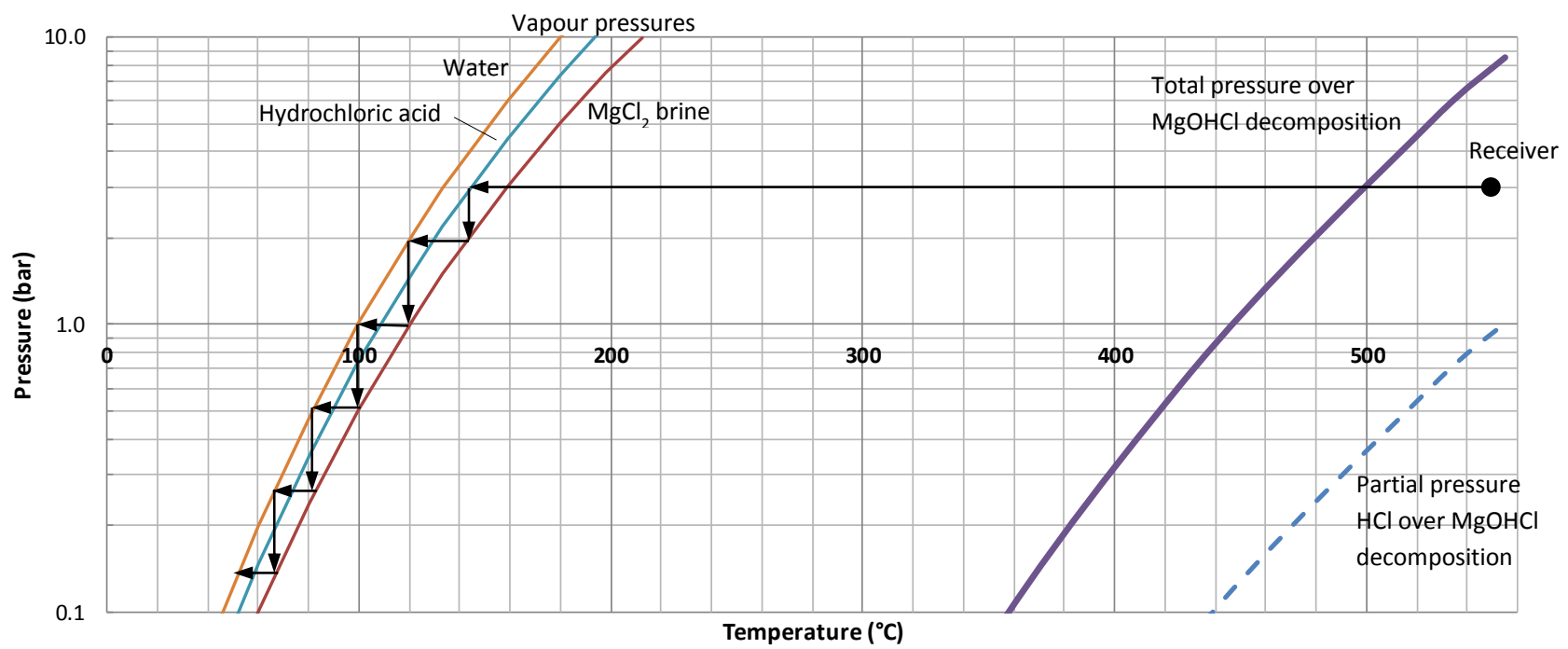

Fig 4: Pressure vs. temperature plots constraining design of the MED and BTD processes: on the left the saturation lines for condensing vapours and evaporating $\mathrm{MgCl}_{2}$ brine (30\% conc.) limit the number of effects in the MED to not more than 5; on the right, the solar volumetric receiver must operate to the right of the bold line representing the total pressure corresponding to the partial pressure of $\mathrm{HCl}$ over decomposing $\mathrm{MgOHCl}$.

Such temperature requires a point focussing solar concentrator and, because of the large scale needed, it is proposed to carry out the operation using a central receiver system with heliostat field. Concentrated brine will be injected into a solar receiver mounted on a tower, where it will vaporise and substantially decompose to yield steam, $\mathrm{HCl}$ and $\mathrm{MgO}$. The design of the receiver has not been attempted in detail, but it is envisaged that - due to the multiphase flow leading to gas-phase output with suspended $\mathrm{MgO}$ particles - a volumetric receiver would be selected. Volumetric receivers have been developed to an advanced stage for use with the air Brayton cycle and have achieved efficiencies of $70-80 \%$ at temperatures of $>1000{ }^{\circ} \mathrm{C} .{ }^{16}$ Losses are dominated by re-radiation which is strongly temperature dependent. ${ }^{17}$ Therefore, at lower temperatures of $550^{\circ} \mathrm{C}$ as used here an efficiency of $90 \%$ is assumed. Additional assumptions include: recovery of sufficient heat from the superheated vapours leaving the receiver to preheat the feed brine to saturation temperature; and no heat recovery from the exiting $\mathrm{MgO}$.

It is interesting to note that the presence of $\mathrm{MgO}$ particles in the flow also implies similarities with solid particle receivers, a type of receiver that is currently being researched due to its potential to provide energy storage. Particles may aid optical absorption, reducing the need for mesh elements inside the receiver. However, these receivers are still at an early stage of development, so it is difficult to draw conclusions about the achievable performance. ${ }^{17}$

\section{Results of modelling}

The results for a BTD-equipped plant (as in Fig.3) of 10000 $\mathrm{m}^{3} /$ day freshwater output are now compared against an unmodified RO plant of the same output. The additional electrical requirement for the NF increases specific energy consumption of the whole plant by $50 \%$ from 3 to 4.5 $\mathrm{kWh} / \mathrm{m}^{3}$ (per total volume freshwater output). To supply the thermal input, the size of the heliostat field is 50 ha. Taking into account the additional electricity usage, the plant will absorb net $18.2 \mathrm{ktCO}_{2} / \mathrm{yr}$ from the atmosphere, compared to $5.3 \mathrm{ktCO}_{2} / \mathrm{yr}$ emissions from the unmodified plant. These results take into account the additional water output from the MED which is only $3.5 \%$ of the RO output. The energy penalties of the process (per mass gross sequestered $\mathrm{CO}_{2}$ ) are: $0.8 \mathrm{GJ} / \mathrm{tCO}_{2}$ and $13 \mathrm{GJ} / \mathrm{tCO}_{2}$ corresponding to electrical and solar thermal energy requirements respectively.

Scale up to 30 billion $\mathrm{m}^{3} / \mathrm{yr}$ freshwater output would require the equivalent of 8200 such plants, with heliostat fields covering about $4000 \mathrm{~km}^{2}$ of land. In total, these plants would absorb $0.15 \mathrm{GtCO}_{2} / \mathrm{yr}$ net which is about $0.4 \%$ of current anthropogenic emissions.

\section{Geological disposal of hydrogen chloride}

Hydrogen chloride leaves the plant as hydrochloric acid (concentration $21 \%$, approximately azeotropic) which must be sequestered to prevent it from returning to the sea. It can react with silicates to yield chlorides and silica, an example being the reaction with olivine:

$\mathrm{Mg}_{2} \mathrm{SiO}_{4}+4 \mathrm{HCl} \rightarrow 2 \mathrm{MgCl}_{2}+2 \mathrm{H}_{2} \mathrm{O}+\mathrm{SiO}_{2}$

The abundance of silicate minerals in the Earth's crust greatly exceeds that needed to offset all $\mathrm{CO}_{2}$ emissions. ${ }^{18}$ However, direct carbonation of silicates has so far been hindered by the slowness of reaction at ordinary temperatures and pressures. Conditions of 150 atm and $185^{\circ} \mathrm{C}$ were required for $\mathrm{CO}_{2}$ to react with powdered silicates over timescales of hours. ${ }^{19}$ In contrast, hydrochloric acid reacted over similar timescales at 
atmospheric pressure and temperatures of only $30-70^{\circ} \mathrm{C}$. In a comparative study of five acids in reaction with serpentine, hydrochloric acid reacted the second fastest after sulphuric acid. $^{20}$ It is believed therefore that injection of hydrochloric acid into silicate rocks would provide a permanent route and fast route to in-situ acid sequestration.

Silicate minerals from the earth's mantle have been brought to the surface through tectonic and volcanic activities in several locations close to where desalination is needed and employed. Examples include: peridotite of the Samail ophiolite in Oman and of the Troodos ophiolite in Cyprus; and laval outflows of mafic rocks approaching the Red Sea coast near Jeddah. The Samail ophiolite alone is theoretically capable of absorbing more $\mathrm{CO}_{2}$ than present in the entire atmosphere and would thus have similarly large capacity to absorb $\mathrm{HCl}^{21}$ The energy requirement of transferring hydrochloric acid to sites of disposal has not been considered in this study. Nonetheless, since the process produces only 28 $\mathrm{kg}$ of hydrochloric acid for each $\mathrm{m}^{3}$ of freshwater desalinated, it is anticipated that this energy will be small in relation to the energy already used in distribution of the freshwater.

\section{Discussion}

\section{Comparison against other options}

The proposed BTD process should be evaluated against other options for neutralising ocean acidity or for removing or avoiding $\mathrm{CO}_{2}$. In general, such comparisons may cover issues of effectiveness, capital and operational costs, energy penalties, land usage, time scales, and environmental impacts and risks. ${ }^{22}$ More broadly, evaluation of geoengineering measures should encompass issues of ethics, governance, and public perception. ${ }^{23}$ Only very preliminary comparisons are possible here pending more extensive studies. Specifically we compare against: (i) ocean liming via calcination of limestone (instead of via thermal decomposition of $\mathrm{MgCl}_{2}$ in seawater); (ii) avoidance of $\mathrm{CO}_{2}$ using concentrated solar power (CSP) to generate electricity (instead of using similar solar plant to achieve the thermal decomposition).

Ocean liming via limestone calcination has been evaluated in depth in a recent study by Renforth et al. ${ }^{6}$ who predicted electrical and thermal energy penalties of 0.1-1.2 and 0.6-5.6 and $\mathrm{GJ} / \mathrm{tCO}_{2}$ respectively. Thus the electrical penalty calculated here for BTD $\left(0.8 \mathrm{GJ} / \mathrm{tCO}_{2}\right)$ is in this range, but the thermal penalty $\left(13 \mathrm{GJ} / \mathrm{tCO}_{2}\right)$ is more than doubled. A breakdown of the thermal energy penalty shows evaporation of water to be the main overhead (Fig 5). In the proposed system, this energy is only recovered in a limited manner to drive the MED and pre-heat the brine feed to the BTD. Therefore improvements should focus on more effective energy recovery. For example, an organic Rankine cycle could be used to extract useful work, or a mechanical vapour compression cycle may enable the condensing vapours to supply enthalpy for the evaporation of the brine prior to it reaching the solar receiver.

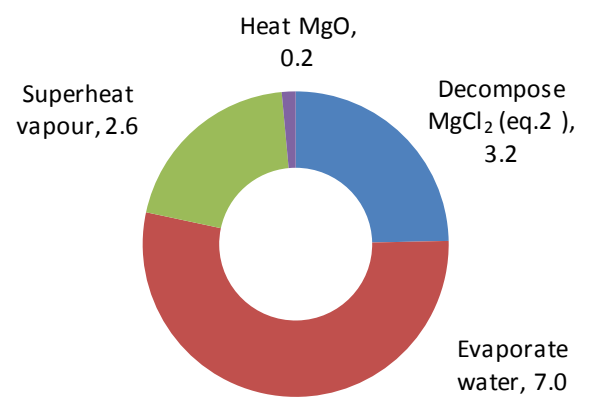

Fig 5: Breakdown of solar thermal energy penalty of brine thermal decomposition (BTD), making up total of $13 \mathrm{GJ} / \mathrm{tCO}_{2}$.

On the other hand, the temperature requirement for BTD is lower than for limestone calcination $\left(550^{\circ} \mathrm{C}\right.$ vs. $\left.850^{\circ} \mathrm{C}\right)$ and so the use of solar energy for BTD appears more feasible. Moreover, mining, calcination and transport of limestone to sites for ocean addition will require very substantial planning and investment in infrastructure, and BTD may be advantageous in avoiding these requirements. Further, calcination of limestone liberates $\mathrm{CO}_{2}$ which has to be sequestered somewhere. Recently a new process of Solar Thermal Electrochemical Decomposition (STEP) of limestone has been put forward which produces $\mathrm{C}$ or $\mathrm{CO}$ rather than $\mathrm{CO}_{2}{ }^{24}$ The process requires solar thermal energy and electrical energy as inputs. The energy budget and scale up of this process would require further evaluation to enable comparison with BTD.

For comparison against CSP, the $10000 \mathrm{~m}^{3} /$ day desalination plant requires a solar field covering 50 ha which is comparable area to the PS10 CSP plant in Spain (land area 55 ha). ${ }^{25}$ As PS10 has net electrical output of about $20 \mathrm{GWh} / \mathrm{yr}$, it avoids an estimated $10 \mathrm{ktCO}_{2} / \mathrm{yr}$ (based on consistent assumption of $0.5 \mathrm{kgCO}_{2} / \mathrm{kWh}$ carbon intensity of substituted electricity). ${ }^{26}$ Per land area, this is only half the absorbed amount expected with the BTD process. PS10 is chosen for comparison, because it is a heliostat plant similar to that envisaged for BTD. Note that other types of solar plant may have greater $\mathrm{CO}_{2}$ avoidance per land area. The preferred choice of CSP plant for a given project can depend on a range of criteria in technical, economic and environmental categories. $^{27}$

\section{Valorisation of hydrochloric acid}

As an alternative to geological disposal of hydrochloric acid, valorisation may be considered. The $10000 \mathrm{~m}^{3} /$ day desalination-BTD plant will produce $100 \mathrm{kt} / \mathrm{yr}$ year of hydrochloric acid at concentration $21 \%$ which could be sold commercially. Since conventional manufacture of hydrochloric acid results in emission of about $0.7 \mathrm{kgCO}_{2} / \mathrm{kg}$, substitution of $100 \mathrm{kt} / \mathrm{yr}$ would result in avoidance of $70 \mathrm{kt}$ $\mathrm{CO}_{2} / \mathrm{yr}$. ${ }^{\diamond}$ This is several times larger than the $18.2 \mathrm{ktCO}_{2} / \mathrm{yr}$ potentially absorbed from the atmosphere by $\mathrm{MgO}$. However, scale up to 30 billion $\mathrm{m}^{3} / \mathrm{yr}$ freshwater output would produce $840 \mathrm{Mt} / \mathrm{yr}$ of hydrochloric acid containing $176 \mathrm{Mt} / \mathrm{yr}$ of $\mathrm{HCl}$ gas. In contrast, current world production of $\mathrm{HCl}$ is reported 
as only $20 \mathrm{Mt} / \mathrm{yr}$, much of which is consumed and produced on site, and open world market size is only $5 \mathrm{Mt} / \mathrm{yr}^{28}$ Therefore production of $176 \mathrm{Mt} / \mathrm{yr}$ could not be absorbed by current world markets.

\section{Local impacts to marine environment}

Ocean discharge of alkaline substance would tend to neutralise acidity globally, but may cause undesired local environmental impacts. $\mathrm{MgO}$ gradually hydrolyses to form $\mathrm{Mg}(\mathrm{OH})_{2}$ which partially dissolves liberating hydroxide ions. Seawater normally has $\mathrm{pH}$ in the range 7.9 to 8.5 , lowered by 0.1 units from pre-industrial levels. ${ }^{29}$ Thus the $\mathrm{pH}$ of the $\mathrm{MgO}$ suspension prepared here $(\mathrm{pH} 9.86)$ is about 1.5 units above natural levels, and $\mathrm{pH}$ would be significantly increased in proximity of the ocean outlet. Hansen ${ }^{30}$ found that growth of phytoplankton slows at high $\mathrm{pH}$. Species C.lineatum, $H$. triqueta and $P$. minimum ceased growing at $\mathrm{pH} 8.8,9.45$ and 9.6 respectively. However, most ecological studies about impacts of $\mathrm{pH}$ focus on acidification, whereas studies concerning local impacts of alkalinity are lacking.

As the $\mathrm{MgO}$ would be discharged together with $\mathrm{NaCl}$ brines, salinity would also be increased, as it is near standard desalination plant. Concerns about impacts of salinity, temperature and chemicals near outlets have prompted detailed modelling and experimental studies. ${ }^{31-33}$ Rapid dispersion and dilution of brines is favoured by long discharge pipes, multiport diffusers, and avoidance of lagoons and shallow waters. ${ }^{32}$ The knowledge and modelling tools already developed in this area could in the future be applied to effective dispersion and mixing of alkaline discharge.

\section{Timescale of absorption of $\mathrm{CO}_{2}$}

Ocean liming is generally considered a long term option for $\mathrm{CO}_{2}$ removal as, due to slowness of gas exchange between the atmosphere and oceans, it could take $>100$ yrs to lower atmospheric $\mathrm{CO}_{2}$ levels. ${ }^{34}$ However, by the same argument, direct atmospheric $\mathrm{CO}_{2}$ reduction or mitigation would be slow to remediate the oceans.

Studies of mineral carbonation have shown that $\mathrm{Mg}(\mathrm{OH})_{2}$ reacts more readily with $\mathrm{CO}_{2}$ than does $\mathrm{MgO}{ }^{35}$ Since the enthalpy of formation of $\mathrm{Mg}(\mathrm{OH})_{2}$ is lower than that of $\mathrm{MgO}$, it could be more energy efficient to use a conversion pathway that produces $\mathrm{Mg}(\mathrm{OH})_{2}$ directly from brine [rather than via $\mathrm{MgO}$ which is then hydrolysed to $\left.\mathrm{Mg}(\mathrm{OH})_{2}\right]$. Future studies of absorption kinetics and timescales could build on the existing models of brine outlets, and would require additional information about the size and dissolution rates of $\mathrm{MgO}$ or $\mathrm{Mg}(\mathrm{OH})_{2}$ particles dispersed in seawater.

\section{Conclusions}

This preliminary study of brine thermal decomposition (BTD) by solar energy has shown that this process could be an interesting variant of ocean liming to help combat ocean acidification and remove atmospheric carbon dioxide. The
BTD process has been studied for application to desalination plant reject. The main findings are:

- Decomposition of $\mathrm{MgCl}_{2}$ in seawater is readily achieved at temperatures $<600^{\circ} \mathrm{C}$, well within the capabilities of solar volumetric receivers heated by heliostat fields.

- The electrical requirement of the desalination plant is increased by about $50 \%$, but this is more than offset by the absorptive capacity of the $\mathrm{MgO}$ produced.

- Electrical energy penalty is in the range estimated for that of ocean liming based on limestone calcination; whereas thermal energy penalty is more than double.

- A doubling of current world desalination capacity could, if equipped with BTD, remove $0.4 \%$ of current anthropogenic emissions requiring heliostat fields covering $4000 \mathrm{~km}^{2}$ of land.

- The land usage per mass of $\mathrm{CO}_{2}$ avoided are competitive against those for equivalent avoidance by means of CSP plants using heliostat fields to generate electricity.

- To reduce thermal energy penalties and land requirements, research is needed into lowering the energy needed to evaporate water from the $\mathrm{MgCl}_{2}$ brine (or recovering more useful energy from condensing $\mathrm{HCl}$ vapours).

In principle the BTD process could be used anywhere with sea access; however, use with desalination has advantages: the infrastructure for intake and discharge already exists; and the seawater is already partially dewatered as reject brine, providing a more suitable feed to the process than raw seawater.

\section{Notes and references}

${ }^{a}$ Sustainable Environment Research Group, School of Engineering and Applied Science, Aston University, Birmingham B4 7ET, UK p.a.davies@aston.ac.uk

$\uparrow$ Methods note: titration was carried out by first dissolving the $\mathrm{MgO}$ in excess $0.5 \mathrm{M} \mathrm{HCl}$ then titrating back to the neutral point with $0.5 \mathrm{M} \mathrm{NaOH}$ to determine the net $\mathrm{HCl}$ needed. Amount of $\mathrm{Mg}$ initially present in samples was determined by conductivity measurement and standard salt composition for seawater was assumed. Experiment repeated 3 times.

* per area of heliostat field, averaged over year.

${ }^{\S}$ based on this study.

$\diamond$ Emission of $0.7 \mathrm{kgCO}_{2} / \mathrm{kg}$ was calculated using Simapro Life Cycle Assessment software (v8.0.2) and Ecoinvent 3 database. Hydrochloric acid (conc. 30\%) manufactured in N. America or Europe was analysed using the CML-IA baseline method v3.01. The result was adjusted to the concentration of $21 \%$ as used in this study.

1. Global Water Intelligence, Market Data, 2012

2. 2030 Water Resources Group, Charting our Water Future, 2009

3. IPCC, Fifth Assessment Report: Summary for Policymakers, 2014.

4. J. Zhou, V. W. C. Chang and A. G. Fane, Desalination, 2013, 308, 233-241.

5. V. Ferrini, C. De Vito and S. Mignardi, Journal of Hazardous Materials, 2009, 168, 832-837.

6. P. Renforth, B. G. Jenkins and T. Kruger, Energy, 2013, 60, 442-452.

7. K. K. Kelley, Technical Paper 676, US Dept of the Interior, 1945.

8. G. Lychnos, R. Amdouni and P. A. Davies, RSC Advances, 2012, 2 , 7978-7982.

9. US Geological Survey, Minerals Information, 2014. 
10.P. A. Davies, K. Turner and C. Paton, in International Engineering Conference, Mutah, 2004, 523-540.

11. R. Robinson and R. Stokes, Electrolyte solutions, Butterworths, London, 1959.

12. H. Ettouney, in Seawater Desalination, eds. A. Cipollina, G. Micale and L. Rizutti, Springer, 2009.

13. P. A. Schweitzer, Corrosion Resistance Tables, Marcel Dekker, 2004

14. J. H. Kim, H. Habazaki, A. Kawashima, K. Asami and K. Hashimuto, Corrosion Science, 1993, 34, 1817-1827.

15. J. S. C. de Bakker, 2011, The recovery of magnesium oxide and magnesium hydroxide from magnesium chloride brines and molten salt hydrates, $\mathrm{PhD}$ thesis, Queen's University, Ontario.

16. A. L. Ávila-Marín, Solar Energy, 2011, 85, 891-910.

17. C. K. Ho and B. D. Iverson, Renewable and Sustainable Energy Reviews, 2014, 29, 835-846.

18. K. S. Lackner, Annual Review of Energy and the Environment, 2002, 27, 193-232.

19. S. J. Gerdemann, W. K. O'Connor, D. C. Dahlin, L. R. Penner and H. Rush, Environmental Science \& Technology, 2007, 41, 2587-2593.

20. S. Teir, H. Revitzer, S. Eloneva, C.-J. Fogelholm and R. Zevenhoven, International Journal of Mineral Processing, 2007, 83, 36-46.

21. P. B. Kelemen and J. Matter, PNAS, 2008, 45, 17295-17300.

22. K. Caldeira, G. Bala and L. Cao, Annu. Rev. Earth. Planet. Science, 2013, 41, 231-256.

23. Royal Society, Geoengineering the climate: science, governance and uncertainty, Policy Document 10/2009, London.

24. S. Licht, H. Wu, C. Hettige, et al., ChemComm, 2012, 48, 6019-6021.

25. http://www.nrel.gov/csp/solarpaces/project_detail.cfm/projectID=38 [accessed 3 Dec 2014].

26. M. Romero, R. Buck and J. E. Pacheo, Trans ASME, 2002, 124, 98 108.

27. J. D. Nixon, P. Dey and P. A. Davies, Energy, 2012, 46, 541-554.

28. R.C. Ropp, Encyclopedia of the Alkaline Earth Compounds, Elsevier, 2012 (p.34)

29. Royal Society, Ocean Acidification due to increasing atmospheric carbon dioxide, Policy Doc 12/2005, London

30. P. Hansen, Aquatic Microbial Ecology, 2002, 28, 279-288.

31. I. Alameddine and M. El-Fadel, Desalination, 2007, 214, 241-260.

32. A. Loya-Fernández. L. M. Ferrero-Vicente, C. Marco-Méndez et al., Desalination, 2012, 217-224.

33. S. Al-Sanea, J. Orfi and A. Najib, 2014, in press, DOI: 10.1080/19443994.2014.940658

34. L. D. D. Harvey, J. Geophys. Res-Oceans, 2008, 113:C04028

35. J. Fagerlund, J. Highfield and R. Zevenhoven, RSC Advances, 2012, 2, 10380-10393.

\section{Broader Context}

Desalination, ocean liming, and concentrated solar power are three technologies that have recently attracted a lot of interest. Seawater desalination by reverse osmosis is being increasingly adopted for municipal water supply. Water is forced at high pressure through membranes which exclude the salt. The energy requirement of the process is significant. Ocean liming is one of several possible geoengineering methods that could be used to influence the Earth's climate. In most schemes it would involve preparation of lime from limestone, by crushing and then heating in a kiln. The lime would then be added to the ocean. Because of the large amounts of lime required, a good deal of investment would be needed in infrastructure to mine and prepare the lime and mix it into the sea. Concentrated solar power is one way to harness solar energy at large scale. It has been studied for use to power desalination but not, as is the case here, to power a process of preparing magnesium oxide (similar to lime) from the seawater brine that leaves a desalination plant. 